Н.В. КУЛАГИНА, ФГБОУ ВО «Северо-Западный государственный медицинский университет им. И.И. Мечникова» Минздрава России, Санкт-Петербург

\title{
СПАЗМОЛИТИЧЕСКАЯ ТЕРАПИЯ
}

\section{ПЕРВИЧНОЙ ДИСМЕНОРЕИ}

\begin{abstract}
Цель исследования. Провести краткий обзор печатных работ, посвященных оценке эффективности и безопасности дротаверина гидрохлорида в лечении спастической боли в животе, обусловленной первичной дисменореей, с анализом применения полученных данных в клинической практике врача акушера-гинеколога. Материалы и методы. Использованы зарубежные и отечественные статьи, отобранные в Pubmed по ключевым словам «дисменорея», «спазмолитическая терапия», «дротаверин», «спазм», «боль». Результаты проанализированных клинических исследований свидетельствуют об эффективности спазмолитической терапии первичной дисменореи препаратом дротаверин гидрохлорид. Заключение. Дротаверин гидрохлорид может быть рекомендован как эффективный и безопасный препарат первого выбора для лечения первичной дисменореи.
\end{abstract}

Ключевые слова: дисменорея, спазмолитическая терапия, дротаверин, спазм.

N.V. KULAGINA, Mechnikov North-Western State Medical University of the Ministry of Health of Russia, St.Petersburg SPASMOLYTIC THERAPY FOR PRIMARY DYSMENORRHEA

Purpose of the study. Perform a brief review of the published works devoted to the evaluation of the effectiveness and safety of drotaverine hydrochloride in the treatment of abdominal cramping caused by primary dysmenorrhea, and an analysis of the use of obtained data in the clinical obstetrician-gynecologist practice. Materials and methods. The authors performed PubMed searches to find foreign and domestic articles using the keywords "dysmenorrhea", "spasmolytic therapy", "drotaverine", "spasm", "pain". The analysis of the clinical studies showed the effectiveness of spasmolytic therapy of primary dysmenorrhea with drotaverin hydrochloride. Conclusion. Drotaverine hydrochloride can be recommended as an effective and safe first-choice drug to treat primary dysmenorrhea.

Keywords: dysmenorrhea, spasmolytic therapy, drotaverine, spasm.

исменорея - циклически повторяющийся болевой синдром, сопровождающий отторжение эндометрия при менструации [1]. Частота дисменореи составляет 12,5-80\% у менструирующих женщин, из них 10\% нетрудоспособны от нескольких часов до 1-4 дней [2]. Дисменорея подразделяется на первичную и вторичную. В девяти из десяти случаев имеет место первичная (идиопатическая) дисменорея. Отмечена зависимость распространенности и структуры патологического процесса от возраста. Среди подростков первичная дисменорея встречается с частотой 43-90\%, достигая максимума на пятом году после менархе. После родов наблюдается уменьшение или исчезновение болевых ощущений во время менструации, также в репродуктивном возрасте чаще встречается дисменорея как результат приобретенных гинекологических заболеваний [1, 3, 4].

Первичная дисменорея - состояние, при котором болевые ощущения во время менструации не связаны со структурными аномалиями. Развивается первичная дисменорея, как правило, с появлением овуляторных циклов и возникает в первый день менструального кровотечения, нарушая качество жизни женщины. Боль продолжается от одних до трех суток и требует применения обезболивающих препаратов. Болевой синдром может сопровождаться развитием вегетативных и вегетативно-сосудистых реакций в виде обморочных состояний, головокружения, головной боли, тошноты и рвоты, диареи, усиления потоотделения, озноба или ощущения жара, частых мочеиспусканий, онемения и парестезии конечностей, колющей боли в сердце [1]. К патологической менструальной боли нередко присоединяются эмоционально-психические нарушения, что создает выраженный дискомфорт, способствует истощению адаптационных резервов нервной системы и развитию астенического состояния, снижает память и работоспособность [5, 6]. Все это вынуждает рассматривать дисменорею не только как медицинскую, но и как серьезную социальную проблему.

Выделяют следующие формы заболевания по степени тяжести: легкую, умеренно выраженную, тяжелую. При легкой форме боль присутствует только в первый день менструации и не имеет сопутствующих системных проявлений, не нарушает обычную активность женщины. Умеренно выраженная дисменорея наблюдается в течение первых двух-трех дней менструации, сочетается с системными жалобами. Болевой синдром нарушает привычный образ жизни пациентки, но редко является причиной потери трудоспособности или отказа от учебы. Тяжелая форма дисменореи проявляется интенсивными болями, развивающимися до начала менструации и продолжающимися от двух до семи дней. Болевой синдром влияет на качество жизни женщины, приводя к снижению и потере трудоспособности [7].

Факторами риска развития первичной дисменореи являются молодой возраст женщины, никотиновая интоксикация, отказ от использования комбинированных оральных контрацептивов (КОК) [8]. Показано, что комбинированные оральные контрацептивы уменьшают выбросы простагландинов, в результате чего снижается сокра- 
тительная маточная активность и боль. Симптомы первичной дисменореи при использовании КОК купируются у 70-80\% женщин [9].

Вторичная дисменорея - симптом каких-либо заболеваний органов малого таза, из которых наиболее частым является эндометриоз. К развитию вторичной дисменореи может привести целый ряд других гинекологических заболеваний: миома матки, воспалительные заболевания органов малого таза, пороки развития матки и влагалища. Боль при этом носит более продолжительный характер, может появляться перед менструальным кровотечением, а во время кровотечения - усиливаться. В целом особенности болевого синдрома (появление ациклических болей, диспареунии), клинических проявлений и тактика лечения вторичной дисменореи зависят от установленного первичного диагноза [10].

В настоящее время основная роль в патогенезе дисменореи отводится метаболитам циклооксигеназы, в том числе простагландинам, тромбоксанам, простациклину. Гиперпродукция и дисбаланс в соотношении данных соединений способствуют возникновению этого патологического состояния. Большинство исследователей связывают возникновение первичной дисменореи с высоким уровнем простагландинов [11]. Боль при дисменорее имеет двоякое происхождение: она возникает в результате маточных сокращений и вторичной ишемии, а также в результате повышения чувствительности тканей к медиаторам боли. У пациенток с болезненными менструациями, сопровождающими овуляторные циклы, концентрация простагландинов в менструальной крови в 2-4 раза выше по сравнению с женщинами, не отмечающими болевого синдрома. Сила сокращений миометрия и величина внутриматочного давления прямо пропорциональны экспрессии простагландинов, то есть чем выше концентрация простагландинов в эндометрии, тем тяжелее протекает дисменорея. Избыточная продукция простагландинов приводит и к нарушению болевой чувствительности. Возникновение болевого ощущения происходит при раздражении нервных окончаний накопившимися альгогенными веществами: простагландинами, лейкотриенами, ионами $\mathrm{Ca}^{2+}$ и $\mathrm{K}^{+}$, выходящими во время менструации во внеклеточное пространство [3, 4].

Высокая продукция простагландинов в эндометрии является процессом гормонозависимым, возникающим при относительной недостаточности прогестерона в незрелом эндометрии. Эстрогены повышают экспрессию провоспалительных цитокинов, простагландинов, что приводит к активации сократительной активности миометрия с появлением болезненных ощущений. Прогестерон, наоборот, тормозит воспаление, опосредованное простагландинами [12], но при относительной его недостаточности, что наблюдается в пубертате, происходит разрушение лизосом эндометриальных клеток и высвобождение фосфолипазы А2 [13], этот фермент конвертирует жирные кислоты в арахидоновую кислоту, которая одновременно является предшественницей простагландинов (синтез опосредован циклооксигеназой) и лейкотриенов (синтез опосредован 5-ипоксигеназой). Таким образом, высокая концентрация прогестерона в нормальном менструальном цикле является одним из факторов, препятствующих гиперпродукции простагландинов и формированию дисменореи.

Как следствие, в результате развивающейся дискоординации сокращений миометрия во время менструации, ишемии тканей, с одной стороны, накапливаются продукты анаэробного метаболизма, которые стимулируют С-тип болевых нейронов, с другой - повышается концентрация простагландинов в тканях. Таким образом, повышенная продукция простагландинов в миометрии в период менструации может носить вторичный характер как реакция на механическое повреждение клеток в результате спазма и ишемии. Снятие спазма разрывает данный порочный круг, тем самым способствуя устранению боли [14].

Определенную патогенетическую роль в гиперактивности миометрия играет гормон задней доли гипофиза вазопрессин. В ряде исследований было установлено возрастание уровня вазопрессина перед менструацией у женщин с дисменореей. Нарушение соотношения «окситоцин/вазопрессин» может приводить к дисритмии маточных сокращений. Связывают развитие дисменореи и с дисморфизмом соединительной ткани вследствие врожденного или приобретенного дефицита внутриклеточного магния [15].

При повышении концентрации простагландинов и ионов кальция и калия в матке может возникать ишемия других органов и тканей, что приводит к экстрагенитальным нарушениям в виде головной боли, рвоты, диареи, кардиалгий и тахикардии [2].

Боль при дисменорее относится к висцеральным болям, то есть вызванным патологическими импульсами, воздействующими на внутренние органы. Висцеральная боль обычно имеет характер тупой боли, но может быть схваткообразная, тянущая, жгущая; в брюшной полости локализована нечетко, так как сенсорные импульсы сразу от нескольких органов поступают в один и тот же сегмент спинного мозга. Лечение висцеральных болей должно проводиться не только классическими обезболивающими препаратами, к каким относятся нестероидные противовоспалительные средства (НПВС), но и фармакологическими средствами, которые сами по себе не являются обезболивающими, но снижают боль путем воздействия на причину возникновения боли. В частности, могут быть использованы спазмолитические препараты, которые снимают боль, возникающую в результате обструкции полых органов, путем прерывания рефлекторного сокращения внутренних органов [16].

Дротаверина гидрохлорид является сильным спазмолитическим агентом, действующим на гладкую мускулатуру независимо от причины возникновения спазма [15]. Согласно инструкции по применению, основной механизм действия препарата обусловлен селективным ингибирующим влиянием на активность фермента, регулирующего процесс мышечного сокращения и расслабления - фосфодиэстеразы 4-го типа (ФДЭ4). При этом не происходит ингибирования ФДЭ-3 и -5, чем объясняется тот факт, что при высокой спазмолитической активности у дротаверина отсутствуют выраженные побочные эффекты со стороны других органов и систем, что выгодно отличает его от про- 
чих спазмолитических и обезболивающих препаратов. Результатом подавления активности ФДЭ4 является накопление внутри клетки циклического аденозинмонофосфата (цАМФ) и, как следствие, ингибирование кальций-опосредованных сокращений гладкой мускулатуры.Дротаверин гидрохлорид снимает причину боли - спазм, тем самым устраняет боль, вызванную спазмом. Препарат быстро всасывается и проникает в разные ткани, хорошо воздействует на повышенный тонус матки. Наряду со спазмолитическим действием на гладкую мускулатуру матки, дротаверин гидрохлорид обладает и сосудорасширяющим эффектом, улучшает кровоснабжение тканей, устраняет ишемию, что в целом способствует купированию болевого синдрома. Серьезных побочных эффектов, связанных с применением препарата, в проведенных исследованиях не выявлено. Общая частота побочных эффектов в соответствии с классификацией Всемирной организации здравоохранения не превышает 0,9\% [17]. У лекарства отсутствует антихолинергическая активность, что обусловливает хорошую переносимость и позволяет комбинировать ее с препаратами других классов. Поэтому в качестве стартовой терапии для устранения боли при менструации оптимален вариант выбора дротаверина гидрохлорида, обладающего хорошим профилем безопасности [18].

С целью изучения эффективности и безопасности использования препарата дротаверина гидрохлорида в лечении первичной дисменореи проводился ряд клинических исследований.

Czinkan T. и соавт. (1971) опубликованы результаты проспективного исследования, проводившегося в течение 4 лет, в котором была показана эффективность использования дротаверина гидрохлорида у 1400 пациенток с различными гинекологическими заболеваниями, в том числе у 175 женщин с дисменореей. Препарат применялся в виде инъекций или перорально в дозе 120 мг/ сут. Эффективность была отмечена у больных дисменореей в 57,1\% наблюдений.

В постмаркетинговом ретроспективном исследовании Maklari L. и соавт (1989) изучали эффективность спазмолитического действия дротаверина гидрохлорида с участием 358 женщин с заболеваниями репродуктивной системы (главным образом дисменореей). Препарат вводили внутримышечно или внутривенно в дозах 40 мг (65\%) и 80 мг (29\%). У 85\% больных отмечено полное купирование боли, у 10\% - частичное; при этом у $85 \%$ пациенток эффект отмечался в течение 30 мин.

В многоцентровом рандомизированном двойном слепом исследовании в двух параллельных группах (протокол DOROTA) проведено сравнение эффективности и переносимости 80 мг дротаверина гидрохлорида и 400 мг ибупрофена у 317 женщин с первичной дисменореей в возрасте от 18 до 35 лет, сопровождающейся сильными и умеренными болями, а также одним или несколькими клиническими симптомами: тошнотой, рвотой, головной болью, слабостью. Выраженность болевых ощущений во время менструации оценивали по 3-балльной системе (0 баллов - отсутствие боли, 1 балл - легкая, 2 балла - умеренная, 3 балла - сильно выраженная боль). Оба препа- рата показали свою эффективность: суммарное снижение выраженности боли за 6-часовой период достоверно не различалось в группах и составило 1,2 \pm 1,18 балла при приеме дротаверина гидрохлорида и 1,7 \pm 0,99 балла при приеме ибупрофена [13].

Целью многоцентрового проспективного перекрестного и долговременного неинтервенционного исследования (протокол M-ASAP), проведенного в Мексике, Казахстане и России, явилась оценка эффективности дротаверина гидрохлорида в повседневной практике лечения спастической боли в животе, обусловленной заболеваниями желудочно-кишечного тракта, желчевыводящих путей и урологического тракта, а также дисменореи [19]. Среди задач исследования также было определение быстроты действия препарата. Боль оценивали по цифровой рейтинговой шкале боли NPRS и визуально-аналоговой шкале (ВАШ). В исследование было включено 5507 пациентов, 86\% пациентов были женщинами, средний возраст которых составил 34,2 \pm 12,5 года, три четверти из них (75,8\%) относились к возрастной группе 18-45 лет. Большинство страдали от дисменореи (53,5\%). Средняя оценка по шкале боли NPRS составляла 6,8 \pm 1,6 балла. 75,5\% проходили лечение дротаверином перорально в суточной дозе 120 Мг со средней продолжительностью 5,7 \pm 4 дней, из них большинство (72,2\%) проходили это лечение в виде монотерапии. 27\% пациентов назначили сопутствующую терапию. Чаще всего сопутствующими препаратами были неопиоидные анальгетики (14,6\%), другие лекарственные средства назначались в 9,6\% случаев. Было три визита: визит включения, визит через три полных дня лечения дротаверином гидрохлоридом, визит завершения через 5 (+3) дней после визита включения. В ходе исследования была отмечена высокая доля пациентов с дисменореей, ответивших на терапию, - 89,4\%. По шкале NPRS, отражающей выраженность боли в течение последних 12 ч, по сравнению с исходным уровнем отмечалось значимое уменьшение средних оценок боли при визите 2, что составило -4,2 \pm 2,2 и -6,2 \pm 2,0 при визите 3 (р < 0,0001 при обоих визитах). Оценка по ВАШ также показала эффективность дротаверина гидрохлорида в уменьшении болевых ощущений при дисменорее: по сравнению оценкой, выполненной через 15 мин после приема препарата, средняя тяжесть боли снижалась через 30 мин (-2,2 \pm 1,3; $p$ < $0,0001)$ и через 60 мин $(-4,4 \pm 1,9 ; p<0,0001)$. Не отмечалось значимых различий в результатах лечения при монотерапии или комбинированной терапии. Преждевременно вышли из исследования по причине отсутствия купирования симптомов 1,6\% пациентов, что позволило сделать вывод о высокой эффективности дротаверина. Была продемонстрирована высокая безопасность препарата сообщений о нежелательных явлениях в ходе исследования не зарегистрировано. Более 66\% пациентов были удовлетворены результатами лечения, а 27\% больных были удовлетворены в высшей степени, и только около 6\% были удовлетворены отчасти. Полученные данные позволяют сделать вывод об эффективности дротаверина в терапии дисменореи и других болевых синдромов, вызванных спазмом гладкой мускулатуры. 
Изучалась результативность терапии первичной дисменореи спазмолитическими препаратами в комбинации с нестероидными противовоспалительными средствами (НПВС). В многоцентровом двойном слепом контролируемом плацебо-рандомизированном исследовании сравнивалась эффективность и безопасность использования комбинации фиксированной дозы ацеклофенака и дротаверина и монотерапии ацеклофенаком в лечении больных первичной дисменорей [20]. В исследование было включено 200 женщин в возрасте от 18 до 35 лет с первичной дисменореей, наблюдавшихся в четырех центрах. Пациентки получали 100 мг ацеклофенака в комбинации с 80 мг дротаверина или монотерапию ацеклофенаком в дозе 100 мг в течение максимум трех дней. Эффективность терапии оценивалась по динамике уменьшения болевых ощущений в группах больных до 4 и 8 ч после приема лекарства, а также различий в интенсивности боли, сумме этих различий интенсивности боли после 4 и 8 ч, максимальном различие интенсивности боли и максимальном облегчении боли после 4 и 8 ч. Также отмечались количество использованных доз препаратов во время лечения и общая оценка пациентами и исследователями качества лечения. В обеих группах наблюдалось значительное уменьшение болевых ощущений на фоне проводимой терапии, однако использование комбинации дротаверина с НПВС достоверно быстрее приводило к уменьшению боли до 4 и 8 ч ( $(p=0,000)$, а также значимо отличались показатели суммы различий интенсивности боли после 4 и 8 ч (р = 0,001). Различия в показателях максимальной интенсивности боли и максимального облегчения боли наблюдались в группах только после 4 ч ( $(=0,001)$, а после 8 ч достоверных различий в группах по этим показателям не наблюдалось ( $>$ > 0,05). Общее количество доз, использованных пациентками в группе получавших комбинированную терапию, было меньше, по сравнению с группой, получавших монотерапию, соответственно 150 и 168 доз. Общая оценка эффективности лечения, данная пациентками и исследователями, была выше в группе, получавшей комбинированную терапию ( $p=0,002)$. Отмечена хорошая переносимость терапии в обеих группах. Комбинация дротаверина с НПВС может быть оценена как высокоэффективная и безопасная терапия больных первичной дисменореей, позволяющая уменьшать дозу используемых препаратов, относящихся группе нестероидных противовоспалительных средств.

Таким образом, обзор проведенных клинических исследований показал сочетание высокой эффективности и безопасности дротаверина гидрохлорида (Но-шпа), что делает препарат оптимальным средством первого выбора для лечения первичной дисменореи.

Приводим клинические наблюдения с применением дротаверина гидрохлорида при первичной дисменорее.

\section{Клинический случай №1.}

Молодая женщина 18 лет обратилась к гинекологу с жалобами на интенсивные боли внизу живота схваткообразного характера, реже ноющие, с иррадиацией в поясницу, регулярно возникающие в первый день менструального цикла. Боли продолжаются не более 48 ч и сопровождаются общим недомоганием. Ежемесячные боли, их ожидание сказывается на общем самочувствие пациентки, делают ее раздражительной, в ряде случаев работоспособность снижается, возникает слабость, что требует пропуска занятий в институте.

Менструации регулярные, с 15 лет, через 28 дней, умеренные, по 5 дней. Половая жизнь - нерегулярная. Беременностей не было. Контрацепция - презерватив.

При осмотре: состояние удовлетворительное. Питание повышенное (ИМТ = 26). Кожа чистая, обычной окраски. чСС 70 уд/мин, АД 120/70 мм рт. ст. Живот мягкий, безболезненный при пальпации во всех отделах. Мочеиспускание и стул не нарушены.

При гинекологическом осмотре наружных половых органов и шейки матки в зеркалах патологических изменений не выявлено. Выделения светлые, слизистые, умеренные. При влагалищном исследовании патологических изменений внутренних половых органов не выявлено.

Онкоцитология - NILM (TSB, 2001).

Мазки на флору - нормоценоз.

УЗИ органов малого таза без патологии.

Клинический анализ крови и анализ мочи общий норма.

Пероральный глюкозотолерантный тест (ПГТТ): натощак - 5,3 ммоль/л и через 2 ч после ГТТ - 7,2 ммоль/л. $\mathrm{HbA} 1 \mathrm{c}-5,2 \%$.

Диагноз «Первичная дисменорея. Избыточная масса тела».

Назначено: В первый и второй дни менструации дротаверина гидрохлорид по 1 таблетке (40 мг) 3 раза в день, при усилении болевого синдрома разовая доза может быть увеличена до 2 таблеток (80 мг).

Диета, занятия спортом.

На приеме через три месяца пациентка удовлетворена проводимой терапией.

\section{Клинический случай № 2.}

Пациентка 23 года, не замужем, испытывает боли в области живота в первый день менструации или за 10-12 ч до ее начала. Работа пациентки связана с длительной статической позой (работа за столом) и со значительным психоэмоциональным напряжением. В первые годы заболевания боли во время менструации были терпимыми, кратковременными и не влияли на работоспособность. С течением времени при увеличении нагрузок на работе, стрессовых ситуаций, боли усилились, увеличилась их продолжительность, появились новые симптомы, сопровождающие боль. Боли обычно продолжаются в течение первого-второго дня цикла, а затем постепенно угасают. По характеру боли схваткообразные с распространением на внутреннюю поверхность бедер. Также отмечается тошнота, общая слабость, тахикардия. Болезненные менструации сопровождаются развитием мигренеподобной головной боли, головокружением, ощущением «ватных ног». Работоспособность нарушается, что требует кратковременного (в течение 1-2 дней) отсутствия на работе.

Менструальный цикл сохранен. Из репродуктивного анамнеза известно, что половая жизнь нерегулярная, 
беременностей не было, контрацепция осуществляется презервативом. У женщины отягощенная наследственность - ее мать отмечала болезненные менструации до первых родов.

При осмотре: состояние удовлетворительное. Питание снижено. Кожные покровы обычной окраски, чистые. АД 120/70 мм рт. ст. При гинекологическом исследовании патологические изменения наружных и внутренних половых органов не выявляются.

При проведении инфекционного и цитологического скрининга патологии не выявлено.

УЗИ органов малого таза: без структурной патологии.

Клинические анализы крови и мочи в пределах нормальных показателей.

При ФГДС: хронический гастродуоденит в стадии ремиссии.

При ЭЭГ определяется преобладание общемозговых изменений с признаками дисфункции мезодиэнцефальных и стриопалидарных структур мозга.
Консультирования невролога: астено-невротический синдром.

Диагноз «Первичная дисменорея. Хронический гастродуоденит, ремиссия. Астено-невротический синдром».

Назначено: дротаверина гидрохлорид по 1 таблетке (40 мг) 3 раза в день.

Препарат магния и витамин В6 в дозировках по инструкции.

Четкий режим труда и отдыха, исключить дополнительные нагрузки во второй фазе менструального цикла и во время менструации. Рекомендованы занятия спортом: плавание.

На приеме через три месяца пациентка удовлетворена проводимой терапией.

Таким образом, дротаверина гидрохлорид может быть рекомендован как эффективный и безопасный препарат для комплексной терапии первичной дисменореи.

Конфликт интересов: авторы заявляют об отсутствии конфликта интересов в ходе написания данной статьи.

\section{ЛИТЕРАТУРА}

1. Якушевская О.В., Ревазова З.В. Микродозированные оральные контрацептивы в терапии дисменореи. РМЖ, 2014, 22(1): 41-44. / Yakushevskaya OV, Revazova ZV. Microdose oral contraceptives in the therapy of dysmenorrhea. RMJ, 2014, 22 (1): 41-44.

2. Сасунова Р.А., Межевитинова Е.А. Современный взгляд на терапию первичной дисменореи. Гинекология, 2009, 1: 60-62. Sasunova RA, Mezhevitinova EA. Contemporary views on the therapy of primary dysmenorrhea. Ginekologiya, 2009, 1: 60-62.

3. Harel Z. Dysmenorhea in adolescents and young adults an update on pharmacological treatments and management strategies. Expert Opinion on Pharmacotherapy, 2012, 13(15): 2157-2170.

4. Ju H, Jones M, Mishra G. The prevalence and risk factors of dysmenorrhea. Epidemiologic Reviews, 2014, 36: 104-113.

5. lacovides S, Avidon I, Bentley A et al. Reduced quality of life when experiencing menstrual pain in women with primary dysmenorrhea. Acta Obstet Gynecol Scand, 2014, 93(2): 213-217.

6. Gagua T, Tkeshelashvili B, Gagua D et al. Assessment of anxiety and depression in adolescents with primary dysmenorrhea: A casecontrol study. J Pediatr Adolesc Gynecol, 2013, 26(6): 350-354

7. Джобава Э.М., Мандрыкина Ж.А., Логинова К.Б., Доброхотова Ю.Э. Дисменорея. Этиопатогенез, дифференциальная диагностика и терапия в практике современного акушера-гинеколога. РМЖ. Акушерство и гинекология, 2012, 1: 28-34. /Jobava EM, Mandrykina ZhA, Loginova KB, Dobrokhotova YuE. Dysmenorrhea. Etiopathogenesis, differential diagnosis and therapy in the modern obstetrician-gynecologist practice. RMJ. Akusherstvo i Ginekologiya, 2012, 1: 28-34

8. Dmitrovic R, Kunselman AR, Legro RS. Continuous compared with cyclic oral contraceptives for the treatment of primary dysmen- orrhea: a randomized controlled trial. Obstet Gynecol, 2012, 119(6): 1143-1150.

9. Нестеровская И.В., Осипова А.А. Неконтрацептивные эффекты гормональных контрацептивов. Ч 1. Дисменорея, эндометриоз, дисфункциональные маточные кровотечения. Акушерство, гинекология и репродукция, 2008 6:11-14. /Nesterovskaya IV, Osipova AA. Noncontraceptive effects of hormonal contraceptives. Part 1. Dysmenorrhea, endometriosis, dysfunctional uterine bleeding. Akusherstvo Ginekologiya i Reproduktsiya, 2008, 6: 11-14.

10. Кузнецова И.В. Проблемы подросткового возраста: когда стоит вмешаться? StatusPraesens. Гинекология, акушерство, бесплодный брак, 2018, 2(45): 87-92. /Kuznetsova IV. Problems of adolescence: when is it worth intervening? StatusPraesens. Ginekologiya, Akusherstvo, Besplodnyy Brak, 2018, 2 (45): 87-92.

11. Возовик А.В., Бажукова Н.Н. Дисменорея у подростков. Репродуктивное здоровье детей и подростков, 2008, 5: 40-42. Nozovik AV, Bazhukova NN. Dysmenorrhea in teenagers. Reproductive health of children and adolescents, 2008, 5: 40-42.

12. Тихомиров А.Л., Юдина Т.А. Патогенетическое обоснование гормонального лечения первичной дисменореи. Репродуктивное здоровье детей и подростков, 2012, 5: 20-24./ Tikhomirov AL, Yudina TA. Pathogenetic substantiation of hormonal treatment of primary dysmenorrhea. Reproduktivnoe Zdorovye Detey i Podrostkov, 2012, 5: 20-24.

13. Debski R, Niemiec T, Mazurec M, Debska M. Comparative efficacy and tolerability of drotaverine $80 \mathrm{mg}$ and ibuprofen $400 \mathrm{mg}$ in patients with primary dysmenorrhea protocol DOROTA. Ginecol, Pol, 2007, 78: 933-938.

14. Джобава Э.М., Логинова К.Б. Дисменорея. Современный взгляд на этиопатогенез и терапию в практике акушера-гинеколога. Акушерство и гинекология, 2014, 11: 23-28./ Jobava EM, Loginova KB. Dysmenorrhea. A modern view of etiopathogenesis and therapy in the obstetrician-gynecologist practice. Akusherstvo i Ginekologiya, 2014, 11: 23-28.

15. Елизаветина Г.А., Минушкин О.Н. Рациональный подход к выбору спазмолитиков для купирования абдоминальной боли. Consilium medicum, 2011, 8: 57-60./ Elizavetina GA, Minushkin ON Rational choice of antispasmodics for relief of abdominal pain. Consilium medicum, 2011, 8: 57-60.

16. Джамберардино М.А. Висцеральная боль. Международная ассощиащия по изучению боли, обновление клинической информащии по боли, 2005, XIII(6): 1-6. Доступно на: http://www. iasppain.org. Доступ был осуществлен в декабре 2011. /Jamberardino MA. Visceral pain. International Association for the Study of Pain, update of clinical information on pain, 2005 , XIII (6): 1-6. Available at: http://www.iasppain org. It was accessed in December 2011.

17. $\operatorname{Tar}$ A, Singer J. Safety profile of NO-SPA ${ }^{\circledR}$ Orvosi Hetilap, 2002, 143: 559-562.

18. Черкасова Н.Ю., Фомина А.В., Филиппова О.В. Алгоритм выбора терапии при лечении дисменореи в рамках консультирования в аптеке. Фарматека, 2013, 6: 38-43. /Cherkasova NYu, Fomina AV, Filippova OV. Algorithm for the choice of therapy to treat dysmenorrhea as part of patient counseling at the pharmacy counter. Pharmateca, 2013, 6: 38-43.

19. Унанян А.Л. Возможности и перспективы применения оригинального дротаверина при дисменорее - результаты международного исследования. Акушерство и гинекология, 2015, 1: 116-123. /Unanyan AL. Opportunities and prospects for the use of original drotaverine in dysmenorrhea: international study results. Akusherstvo i Ginekologiya, 2015, 1: 116-123.

20. Pareek A, Chandurkar NB, Patil RT, Agrawal SN, Uday RB, Tambe SG. Efficacy and safety of aceclofenac and drotaverine fixed-dose combination in the treatment of primary dysmenorrhoea: a double-blind, double-dummy, randomized comparative study with aceclofenac. European Journal of Obstetrics \& Gynecology and Reproductive Biology, 2010, 152(1): 86-90.

\section{СВЕДЕНИЯ ОБ АВТОРЕ:}

Кулагина Наталья Владимировна - д.м.Н., профессор кафедры акушерства и гинекологии ФГБОУ ВО «Северо-Западный государственный медицинский университет им. И.И. Мечникова» Минздрава России, Россия, Санкт-Петербург 